\title{
Use of transcutaneous oxygen tension, arterial oxygen saturation, and respiratory resistance to assess the response to inhaled methacholine in asthmatic children and normal adults
}

\author{
Nicola M Wilson, Stephen B Phagoo, Michael Silverman
}

\begin{abstract}
Respiratory resistance $\left(\mathbf{R r s}_{6}\right)$, transcutaneous oxygen tension $\left(\mathrm{PtcO}_{2}\right)$, and oxygen saturation $\left(\mathrm{SaO}_{2}\right)$ were measured during methacholine challenge in 15 asthmatic children and six normal adults. During bronchoconstriction, induced by a wide range of inhaled methacholine concentrations $(0 \cdot 5-256 \mathrm{~g} / 1)$, the rise in $\mathrm{Rrs}_{6}$ was reflected by a fall in $\mathrm{Ptco}_{2}$ in all subjects. Although there was a significant mean fall in $\mathrm{SaO}_{2}$ at maximum bronchoconstriction there was no consistent relation between changes in $\mathrm{SaO}_{2}$ and $\mathbf{R r s}_{6}$. The inhaled dose of methacholine causing a $40 \%$ increase in $\mathbf{R r s}_{6}$ $\left(\mathbf{P D}_{40} \mathbf{R r s}_{6}\right)$ and a $20 \%$ fall in $\mathbf{P t c o}_{2}$ $\left(\mathrm{PD}_{20} \mathrm{PtcO}_{2}\right)$ was calculated for each subject. There was no significant difference in mean $\mathbf{P D}_{40} \mathrm{Rrs}_{6}$ and $\mathbf{P D}_{20} \mathbf{P t c O}_{2}$, and the relation between the two was similar in the asthmatic children and the normal adults. It was therefore concluded that the measurement of $\mathrm{PtcO}_{2}$, but not $\mathrm{SaO}_{2}$, during methacholine challenge can be used for the assessment of bronchial responsiveness, and that it could prove particularly useful for children too young to cooperate with lung function tests.
\end{abstract}

Little is known about the development of bronchial responsiveness and its relation to respiratory symptoms in early childhood. The main difficulty has been the inability of very young children to cooperate with lung function testing. Many workers have noted that hypoxaemia occurs in association with bronchoconstriction during bronchial challenge $\mathrm{i}^{1-3}$ and some have used measurement of transcutaneous oxygen tension $\left(\mathrm{PtcO}_{2}\right)$ instead of respiratory resistance ( $\mathrm{Rrs}$ ) to measure the response to methacholine inhalation challenge in older children and sedated preschool children. ${ }^{45}$

The purpose of this study was to find out whether there was a consistent relation between changes in $\mathrm{PtcO}_{2}$ and $\mathrm{Rrs}$ during methacholine challenge, and whether a particular change in $\mathrm{PtcO}_{2}$ could be used to calculate a provocative dose of methacholine in children too young to cooperate with lung function tests. Because the measurement of arterial oxygen saturation $\left(\mathrm{SaO}_{2}\right)$ is simpler and more readily available than that of $\mathrm{PtcO}_{2}$, $\mathrm{SaO}_{2}$ was measured simultaneously. So that we could examine the relation between bronchoconstriction and hypoxaemia over a wide range of inhaled methacholine concentrations, we studied normal adults and asthmatic children.

\section{Method}

SUBJECTS

Nineteen asthmatic children (age range 4-11 years) were selected from the children's asthma clinic. All were in a stable condition but represented a wide range of clinical severity. All bronchodilator and cromoglycate treatment was stopped at least 12 hours before the study. Six normal adult volunteers aged 23-46 years were recruited (table).

The study had approval from the hospital ethics committee and informed consent was obtained from all subjects and where applicable their parents.

\section{CHALLENGE PROCEDURE}

After the subject had inhaled normal saline doubling concentrations of methacholine chloride were administered for one minute each, by Wright nebuliser, with $81 / \mathrm{min}$ of air as the driving gas. The initial concentration was $0.5 \mathrm{~g} / 1$ for asthmatic subjects and 4-16 g/1 for normal subjects. The subject breathed quietly through a mouthpiece with a nose clip in place. The inhalations were repeated at five minute intervals until a $40 \%$ increase in respiratory resistance had occurred or the maximum concentration of methacholine (32 $\mathrm{g} / \mathrm{l}$ for asthmatic children and $256 \mathrm{~g} / 1$ for normal adults) had been delivered. The same nebuliser was used throughout the study.

\section{LUNG FUNCTION}

Respiratory resistance was measured by the forced oscillation technique with the apparatus designed and built by Landser. ${ }^{6}$ The subject sat resting on his elbows with a nose clip in place and cheeks supported while breathing normally into the apparatus through a mouthpiece. Rrs was determined over the frequency spectrum $2-26 \mathrm{~Hz}$. The average $\mathrm{Rrs}$ over the whole frequency range and Rrs at each oscillation frequency were recorded. Only values with a coherence of at least 0.95 (signal to noise ratio) were accepted. As $6 \mathrm{~Hz}$ was the lowest single frequency that consistently produced a value of Rrs with an acceptable coherence in all subjects, this value of $\operatorname{Rrs}\left(\mathrm{Rrs}_{6}\right)$ was used to assess the response to methacholine inhalation. The $\mathrm{Rrs}_{6}$ values were compared with predicted values. ${ }^{\text {? }}$ 
Lung function and bronchial responsiveness in asthmatic children and normal adults

\begin{tabular}{|c|c|c|c|c|c|c|c|c|c|c|}
\hline $\begin{array}{l}\text { Subject } \\
\text { No }\end{array}$ & Age (y) & Sex & $\begin{array}{l}\text { Baseline } \\
\text { Rrs }_{6} \\
\left(\% \text { pred }^{7}\right)\end{array}$ & $\begin{array}{l}\text { COV } \\
\operatorname{Rrs}_{6} \\
(\%)\end{array}$ & $\begin{array}{l}\text { Baseline } \\
\mathrm{PtCO}_{2} \\
(\mathrm{kPa})\end{array}$ & $\begin{array}{l}\mathrm{COV} \\
\mathrm{PtCO}_{2} \\
(\%)\end{array}$ & $\begin{array}{l}\text { Correlation } \\
\Delta \operatorname{Rrs}_{6}: \triangle \mathrm{PtCO}_{2} \\
(\mathrm{r})\end{array}$ & $\begin{array}{l}P D_{40} R r s_{6} \\
(\mu \mathrm{mol})\end{array}$ & $\begin{array}{l}\mathrm{PD}_{20} \mathrm{PtCO}_{2} \\
(\mu \mathrm{mol})\end{array}$ & $\begin{array}{l}\mathrm{PD}_{15} \mathrm{PtCO}_{2} \\
(\mu \mathrm{mol})\end{array}$ \\
\hline 1 & 9 & $\mathbf{M}$ & 174 & 5 & $12 \cdot 7$ & 3 & -0.84 & $1 \cdot 8$ & $1 \cdot 0$ & 0.5 \\
\hline 2 & 7 & $\mathrm{~F}$ & 185 & 12 & $10 \cdot 7$ & 2 & $-0.90^{\star}$ & 1.5 & $2 \cdot 0$ & $1 \cdot 2$ \\
\hline 3 & 5 & $\mathrm{M}$ & 146 & 6 & $11 \cdot 4$ & 1 & $-0.92^{\star}$ & 1.9 & $2 \cdot 7$ & 1.7 \\
\hline 4 & 10 & $\mathrm{M}$ & 139 & 9 & $10 \cdot 1$ & 2 & $-0.96^{\star}$ & 0.2 & 0.7 & 0.3 \\
\hline 6 & 4 & M & 103 & 7 & $10 \cdot 7$ & 4 & -0.68 & 0.9 & 0.5 & 0.3 \\
\hline 7 & 6 & $\mathbf{M}$ & 127 & 9 & $9 \cdot 0$ & 2 & $-0.95^{\star}$ & 0.9 & 2.5 & 1.6 \\
\hline 8 & 6 & $\mathbf{M}$ & 147 & 18 & $10 \cdot 1$ & 2 & $-0.99 \star \star$ & 5.9 & $2 \cdot 4$ & 1.8 \\
\hline 9 & 6 & $\mathrm{~F}$ & 95 & 10 & $8 \cdot 4$ & 3 & -0.86 & $5 \cdot 8$ & $8 \cdot 8$ & 6.0 \\
\hline 10 & 7 & $\mathbf{M}$ & 77 & 13 & $9 \cdot 5$ & 1 & -0.84 & $7 \cdot 8$ & $11 \cdot 0$ & $7 \cdot 0$ \\
\hline 11 & 6 & $\mathbf{M}$ & 66 & 6 & $9 \cdot 1$ & 3 & -0.66 & 3.9 & 4.5 & $3 \cdot 6$ \\
\hline 12 & 6 & $\mathbf{M}$ & 130 & 16 & $10 \cdot 1$ & 1 & $-0.96^{\star \star}$ & 11.0 & $9 \cdot 1$ & $7 \cdot 5$ \\
\hline 13 & 10 & $\mathbf{F}$ & 80 & 15 & $12 \cdot 3$ & 2 & -0.86 & $9 \cdot 7$ & $11 \cdot 0$ & $6 \cdot 3$ \\
\hline 14 & 10 & F & 82 & 9 & $10 \cdot 1$ & 1 & $-0 \cdot 89 \star \star$ & $21 \cdot 0$ & $22 \cdot 0$ & $10 \cdot 0$ \\
\hline 15 & 11 & $\mathbf{M}$ & 109 & 12 & 10.9 & 3 & -0.59 & 0.6 & 0.9 & $0 \cdot 7$ \\
\hline
\end{tabular}

Geometric mean

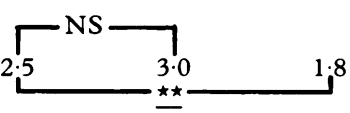

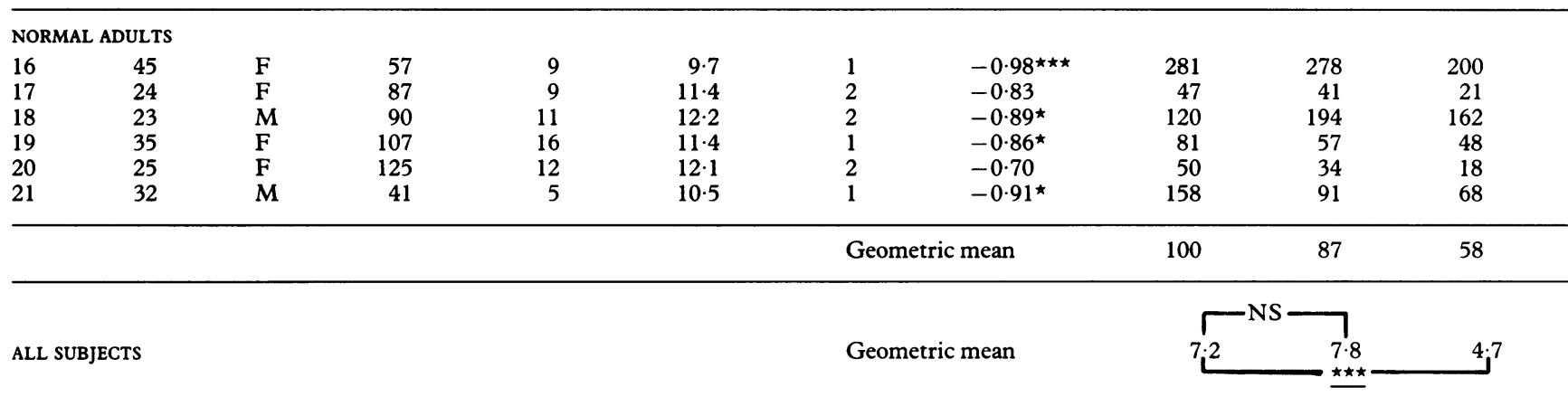

${ }^{\star} \mathrm{p}<0.05,{ }^{\star \star} \mathrm{p}<0.01,{ }^{\star \star \star} \mathrm{p}<0.001$.

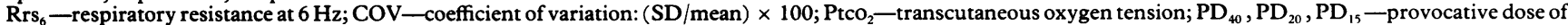
methacholine causing a $40 \%, 20 \%$, and $15 \%$ fall in the measurement specified.

TRANSCUTANEOUS OXYGEN

$\mathrm{PtcO}_{2}$ (Radiometer TCM3, Copenhagen) was measured with a combined skin electrode (oxygen and carbon dioxide) at $44^{\circ} \mathrm{C}$ placed on the anterior chest wall. The electrode was calibrated with $20.9 \%$ oxygen and $5 \%$ carbon dioxide before each study. At the end of each study electrode calibration was checked to ensure that drift did not exceed $0 \cdot 1 \mathrm{kPa}$. After at least a 20 minute equilibration period baseline values were obtained manually at minute intervals for eight minutes. After each challenge inhalation values were recorded at precisely one minute intervals. $\mathrm{SaO}_{2}$ was recorded simultaneously with a Novametrix 500 (Wallingford, Connecticut) pulse oximeter with a finger probe.

The partial pressure of transcutaneous carbon dioxide $\left(\mathrm{PtCCO}_{2}\right)$ was measured in addition to $\mathrm{PtcO}_{2}$ in 12 subjects during methacholine challenge with the combined electrode.

\section{ANALYSIS}

Change in $\mathrm{Rrs}_{6}$ was plotted against $\mathrm{Ptco}_{2}$ and $\mathrm{SaO}_{2}$ with increasing doses of methacholine for each subject. Correlation coefficients were calculated and the significance of the relationship was calculated by means of regression analysis.

The cumulative doses of methacholine delivered-that is, the concentration times nebuliser output $(0.14(\mathrm{SD} 0.01) \mathrm{ml} / \mathrm{min})$ that produced a $40 \%$ increase in $\mathrm{Rrs}_{6}\left(\mathrm{PD}_{40} \mathrm{Rrs}_{6}\right)$ and a $15 \%$ and $20 \%$ fall in $\mathrm{Ptco}_{2}\left(\mathrm{PD}_{15} \mathrm{Ptco}_{2}\right.$ and $\mathrm{PD}_{20} \mathrm{Ptco}_{2}$ )-were calculated by interpolation from the log dose-response curves for each subject. Changes were calculated from the mean baseline values.

A paired $t$ test was used to compare the difference between $\mathrm{PD}_{40} \mathrm{Rrs}_{6}$ and $\mathrm{PD}_{15} \mathrm{PtcO}_{2}$ and $\mathrm{PD}_{20} \mathrm{PtcO}_{2}$ for the group as a whole. Values are given as means with $\mathrm{SD}$ in parentheses. A p value below 0.05 was accepted as statistically significant.

\section{Results}

Fifteen children and all six adults completed technically satisfactory studies. The results of four children were rejected, in three because they did not develop a $40 \%$ increase in $\mathrm{Rrs}_{6}$ and in one because no dose-response relationship was seen for any variable with increasing methacholine.

\section{BASELINE MEASUREMENTS}

The intrasubject coefficient of variation for baseline measurements of $\mathrm{Rrs}_{6}$ (based on six measurements) and $\mathrm{PtcO}_{2}$ (eight observations) are shown in the table. The intrasubject variation in baseline measurements of $\mathrm{SaO}_{2}$ (eight observations) varied from zero to $2 \%$ (mean $0 \cdot 8 \%$, SD 0.75). 
Figure 1 Change in respiratory resistance at $6 \mathrm{~Hz}\left(\mathrm{Rrs}_{6}:-\longrightarrow\right)$ and transcutaneous oxygen tension ( $\mathrm{PtcO}_{2}:----$ ) with increasing doses of inhaled methacholine in (a) an asthmatic child and (b) a normal adult. The shown as means and $95 \%$ confidence intervals. baseline values $(B)$ are

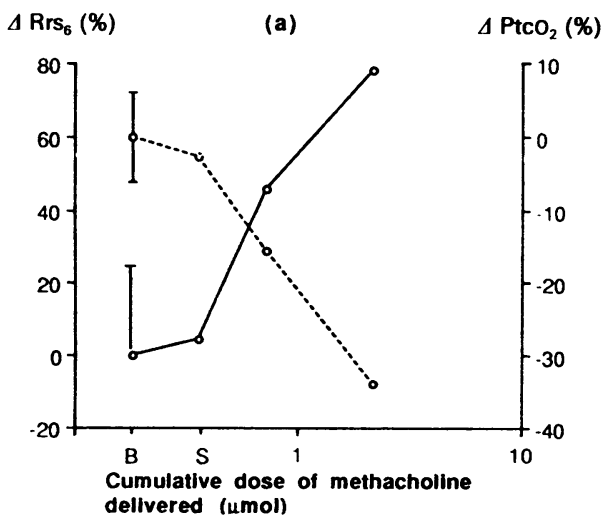

RELATION OF CHANGE IN $\mathrm{Rrs}_{6}$ AND $\mathrm{PtCO}_{2}$ DURING METHACHOLINE CHALLENGE

The rise in $\mathrm{Rrs}_{6}$ was associated with a significant fall in $\mathrm{PtCO}_{2}$ for each subject (that is, $>2 \mathrm{SD}$ below the mean baseline value for that subject). The mean fall in $\mathrm{PtcO}_{2}$ was significant for both normal ( $p<0.001$ ) and asthmatic children ( $p$ $<0.001)$. There was a significant inverse relation between $\Delta \mathrm{Rrs}_{6}$ and $\Delta \mathrm{PtCO}_{2}$ in 12 of the 21 subjects (eight children, four adults) (table). Change in $\mathrm{Rrs}_{6}$ and $\mathrm{Ptco}_{2}$ with increasing doses of inhaled methacholine in an asthmatic child and a normal adult are shown in figure 1 .

RELATION BETWEEN Rrs 6 AND $\mathrm{PtCO}_{2}$

The $\mathrm{PD}_{40} \mathrm{Rrs}_{6}$ was closer to the $\mathrm{PD}_{20} \mathrm{Ptco}_{2}$ than to the $\mathrm{PD}_{15} \mathrm{PtcO}_{2}$. There was no significant difference between the mean $\mathrm{PD}_{40} \mathrm{Rrs}_{6}$ and mean $\mathrm{PD}_{20} \mathrm{Ptco}_{2}$ for adults or children $(2.5 v 3.0$ for children; $7 \cdot 2 v 7 \cdot 8$ for adults), whereas mean $\mathrm{PD}_{15} \mathrm{Ptco}_{2}$ was significantly lower for both ( $1 \cdot 8$ and $4.7 \mu \mathrm{mol}$; table). The relation between $\mathrm{PD}_{40} \mathrm{Rrs}_{6}$ and $\mathrm{PD}_{20} \mathrm{Ptco}_{2}$ was similar over a wide range of inhaled methacholine doses, though the scatter was slightly wider among the children (figs 2 and 3). The difference between the two was within 1 doubling dilution of methacholine in all adults and in 12 of the 15 children. The difference in the remaining three children was within 2 doubling dilutions.

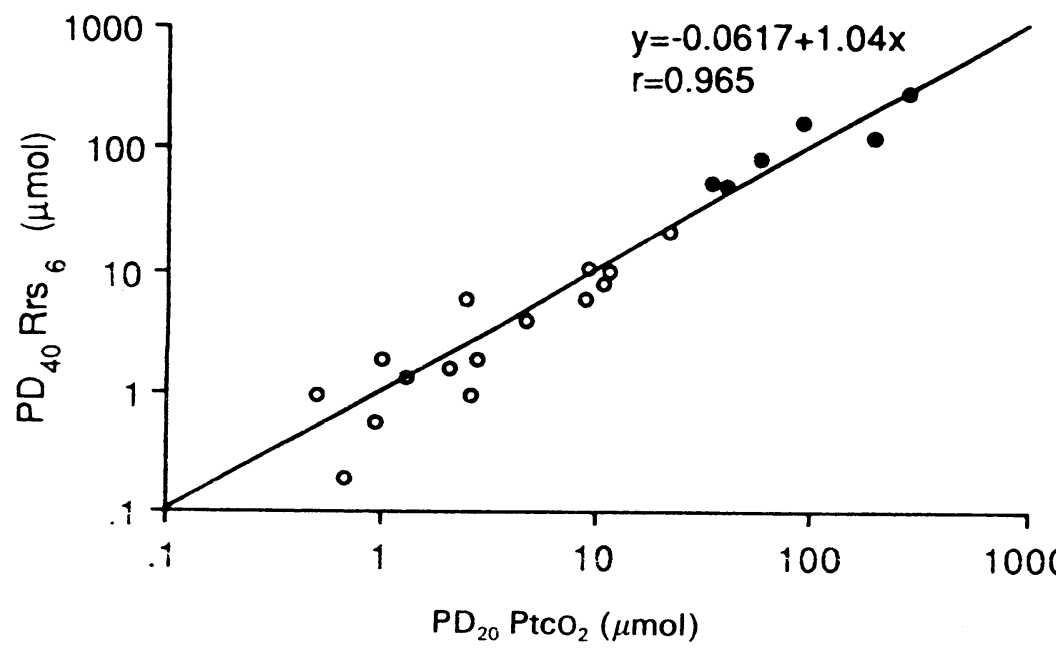

Figure 2 Relation between $\mathrm{PD}_{40} \mathrm{Rrs}_{6}$ and $\mathrm{PD}_{20} \mathrm{PtCO}_{2}$, with the line of identity, in normal adults (O) and asthmatic children ( $)$. Abbreviations as in figure 1.

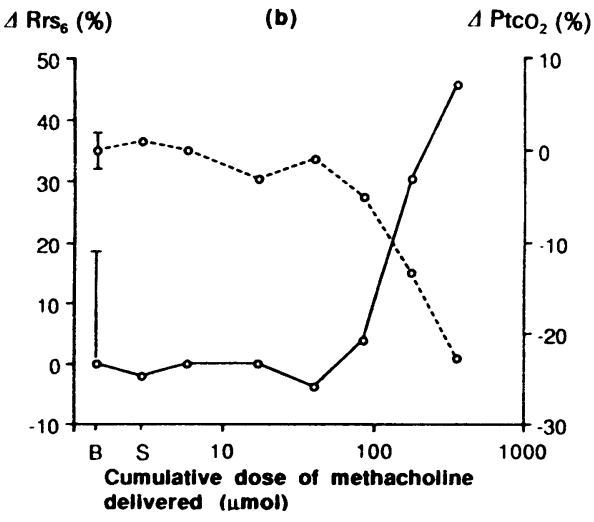

RELATION OF $\mathrm{Rrs}_{6}$ AND $\mathrm{SaO}_{2}$

There was a significant fall in $\mathrm{SaO}_{2}$ at the time of maximum bronchoconstriction for the group as a whole, from a mean value of $97 \cdot 2 \%$ (SD $1 \cdot 19 \%$ ) to $94.4 \%(3 \cdot 36 \%) ; p<0.001$. Five subjects showed a significant relation between $\Delta \mathrm{Rrs}_{6}$ and $\Delta \mathrm{SaO}_{2}$. The maximum fall was $2 \%$ or less in 12 subjects, however, which was within the $95 \%$ confidence limits for repeat baseline measurements. We could not therefore determine a given fall in $\mathrm{SaO}_{2}$ that could be used universally to define a provocative dose.

There was no change in mean $\mathrm{PtcCO}_{2}$ (at rest $4.94(0.55))$, at maximum dose of methacholine $4.94(0.38) \mathrm{kPa}$.

\section{Discussion}

Bronchoconstriction induced by methacholine in both asthmatic children and normal adults, caused a fall in $\mathrm{PtcO}_{2}$. A 20\% fall in $\mathrm{PtcO}_{2}$ was roughly equivalent to a $40 \%$ increase in $\mathrm{Rrs}_{6}$ for bronchoconstriction induced by a very wide range of methacholine doses.

The cause of the fall in $\mathrm{Ptco}_{2}$ is not clear. It cannot be attributed to hypoventilation as there was no rise in $\mathrm{PtcCO}_{2}$. Stewart and colleagues found that histamine but not methacholine challenge induced changes in breathing pattern, including minute ventilation, though both were associated with significant desaturation and similar degrees of bronchoconstriction. $^{2}$

The most likely cause of the induced fall in $\mathrm{PtCO}_{2}$ is an increase in ventilation-perfusion $(\dot{V} / \dot{Q})$ mismatch, caused either by airway narrowing or by an effect on the pulmonary circulation. If the latter is a factor it is likely to be secondary to bronchoconstriction as the fall in $\mathrm{PtcO}_{2}$ was closely related to changes in lung function over a very wide range of inhaled methacholine doses. This is in contrast to the dissociation between change in lung function and arterial oxygen tension seen after treatment of induced bronchoconstriction with bronchodilators. ${ }^{8-10}$

Hedlin and colleagues found evidence of $\dot{\mathrm{V}} / \dot{\mathrm{Q}}$ mismatching after histamine inhalation in asthmatic children," with one normal and one high $\dot{V} / \dot{Q}$ mode as a result of hyperinflation associated with bronchoconstriction.

Mean baseline $\mathrm{Ptco}_{2}$ ranged from $8 \cdot 4$ to $12 \cdot 7$ $\mathrm{kPa}$ in the children and from 9.7 to $12.2 \mathrm{kPa}$ in the adults; it was unrelated to baseline $\operatorname{Rrs}_{6} \%$ 


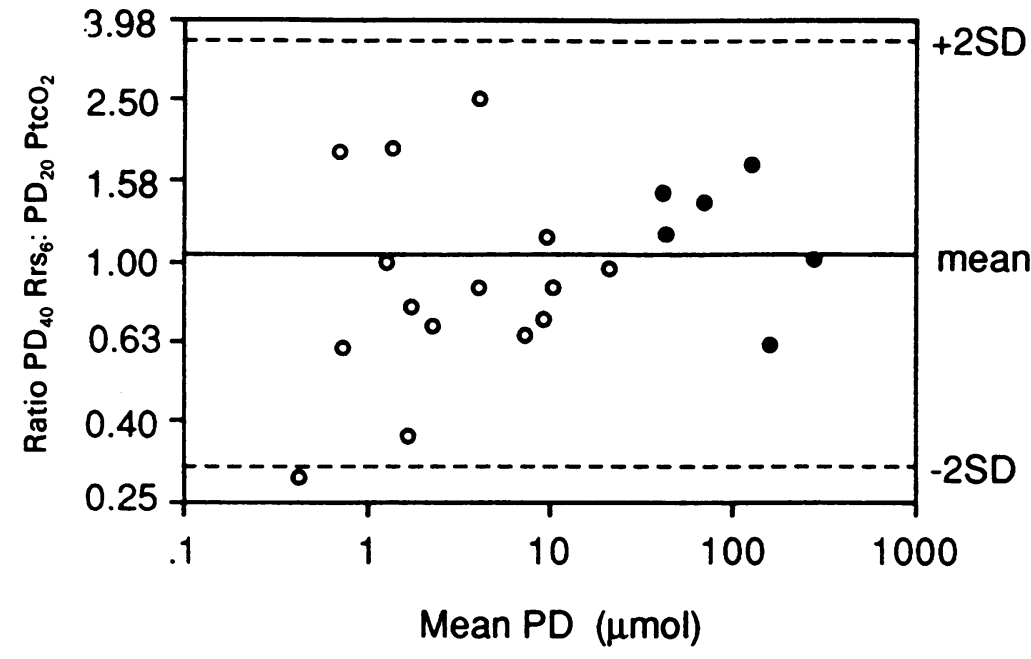

Figure 3 Ratio of $\mathrm{PD}_{40} \mathrm{Rrs}_{6}$ to $\mathrm{PD}_{20} \mathrm{PtCO}_{2}$ plotted against their means, showing no systematic variation between the two values over the range of inhaled methacholine doses, in normal adults (O) and asthmatic children (O). Abbreviations as in figure 1.

predicted or to methacholine $\mathrm{PD}_{40} \mathrm{Rrs}_{6}$ (table). The differences between subjects are probably related to wide variations in skin $\mathrm{Po}_{2}$ conductance. Without in vivo calibration the measurement of $\mathrm{PtcO}_{2}$ does not accurately reflect $\mathrm{PaO}_{2}$ but it is a reliable monitor of change in $\mathrm{PaO}_{2} .{ }^{9}$ In all the subjects $\mathrm{SaO}_{2}$ was within the normal range (96-98\%). Dal Negro and coworkers have shown that bronchoconstriction induced by inhalation of ultrasonically distilled water is associated with a similar fall in $\mathrm{PtcO}_{2}$ and directly measured arterial oxygen tension in asthmatic subjects. ${ }^{3}$

The lack of a significant relation between $\Delta \mathrm{Rrs}_{6}$ and $\Delta \mathrm{Ptco}_{2}$ in some subjects may be due to the small number of measurements in subjects who responded to a low dose of methacholine. Another variable is the possible effect of lung volume changes on measurement of airways resistance. During methacholine challenge Buhr and colleagues found a mean increase in $\mathrm{Rrs}_{6}$ of $48 \%$ and in Raw of $63 \%$ compared with a $98 \%$ increase in Raw when this was related to lung volume (sRaw). ${ }^{12}$

The lack of sensitivity of $\mathrm{SaO}_{2}$ to induced bronchoconstriction would be expected from the sigmoid shape of the oxygen dissociation curve, most subjects requiring a greater degree of bronchoconstriction to show a change in $\mathrm{SaO}_{2}$ than in $\mathrm{Ptco}_{2}$. There was, however, considerable variation in the $\mathrm{SaO}_{2}$ response in both adults and children, six subjects showing a change in $\mathrm{SaO}_{2}$ of more than $2 \%$ with an increase of $\mathrm{Rrs}_{6}$ of $30 \%$ or less, whereas others showed no change despite a $40 \%$ increase in $\mathrm{Rrs}_{6}$. Desaturation during bronchoconstriction was not related to baseline values of $\mathrm{PtcO}_{2}$.

The intrasubject coefficient of variation of repeated measurement of Rrs varied widely (table), as reported by others. ${ }^{713}$ Perhaps Rrs therefore was not the ideal lung function measurement to use as the gold standard with which to compare changes in $\mathrm{Ptco}_{2}$. It was chosen as it was the only lung function measurement that did not interfere with oxygenation. The full inspiration of deep breath tests such as $\mathrm{FEV}_{1}$ causes $\mathrm{Ptco}_{2}$ to rise.
By comparing changes in $\mathrm{Rrs}$ and $\mathrm{PtCO}_{2}$, Mochizuki and coworkers ${ }^{4}$ calculated a threshold dose of methacholine (that which caused a response that just exceeded confidence limits for the baseline values of both variables) for each subject and found a good correlation between the two. Their method has the advantage that a lower dose of methacholine can be given; but for Rrs, where the differences in intrasubject repeatability are wide, the provoking concentration or dose would have been measured at different levels of bronchoconstriction in different subjects.

Although we found that a $20 \%$ fall in $\mathrm{Ptco}_{2}$ could confidently be used to define a PD methacholine, we have not formally assessed the repeatability of such a measurement.

When three of the normal adults repeated the protocol six months later, the intrasubject variations in $\mathrm{PD}_{40} \mathrm{Rrs}_{6}$ and $\mathrm{PD}_{20} \mathrm{PtcO}_{2}$ were similar and both were within a doubling dilution of methacholine (ratios of first to second values $0.94,1.53$, and 1.53 for $\mathrm{PD}_{40} \mathrm{Rrs}_{6}$ and $0.82,1.52$, and 1.13 for $\left.\mathrm{PD}_{20} \mathrm{Ptco}_{2}\right)$. This suggests that $\mathrm{PD}_{20} \mathrm{Ptco}_{2}$ methacholine will prove to be as repeatable as PD measurements derived from more conventional lung function tests.

The development of an indirect method to reflect changes of lung function during inhalation challenge has been necessary as currently no lung function techniques are suitable for the 1-5 year age group. The oscillation technique has been recommended for measurement of lung function in children as young as 2 years, ${ }^{14}$ but it is not practicable in unsedated children under 5 years when repeated measurements are needed. The present study could therefore only be performed in older children. As no age related differences were seen in the relation between the fall in $\mathrm{Ptco}_{2}$ and induced bronchoconstriction, we may reasonably assume that a similar relation between the two exists in children too young to cooperate with standard lung function tests. The measurement of $\mathrm{PtCO}_{2}$ alone during inhalation challenge in preschool children should prove an easy and well tolerated method with which to determine bronchial responsiveness in this age group.

We are grateful to the National Asthma Campaign for its continued support.

1 Poppius $\mathrm{H}$, Stenius B. Changes in arterial oxygen saturation in patients with hyperactive airways during histamine inhalation test. Scand J Respir Dis 1977;58:1-4.

2 Stewart IC, Parker A, Catterall JR, Douglas NJ, Flenley DC. Effect of bronchial challenge on breathing patterns and arterial oxygenation in stable asthma. Chest 1989;95: and arteri.

3 Dal Negro R, Allegra L. Blood gas changes during and after nonspecific airway challenge in asthmatic and norma subjects. J Appl Physiol 1989;67:2627-30.

4 Mochizuki H, Mitsuhashi M, Tokuyama K, Tajima K, Morihawa A, Kuroume T. A new method of estimating bronchial hyperresponsiveness in younger children. Ann Allergy 1985;55:162-6.

5 Mochizuki H, Mitsuhashi M, Tokuyama K, Tajima K, Morihawa A, Kuroume T. Bronchial hyperresponsiveness in younger children with asthma. Ann Allergy 1988; 60:103-6.

6 Landser FF, Nagels J, Demedts M, Billiet L, van de Woestigne KP. A new method to determine frequency characteristics of the respiratory system. J Appl Physiol 1976;41:101-6. 
7 Duiverman EJ, Clement J, van de Woestigne KP, Neigens HJ, van de Bergh ACM, Kerrebijn KF. Forced oscillation technique reference values for resistance and reactance over a frequency spectrum of $2-26 \mathrm{~Hz}$ in healthy children 2.3-12.5 years. Bull Eur Physiopathol Respir 1985;21: $171-8$.

8 Rodriguez-Roisin R, Wagner PD. Clinical relevance of ventilation perfusion inequality determined by inert gas ventilation perfusion inequality determinec

9 Pradal V, Braggion C, Mestella G. Transcutaneous blood gas analysis during sleep and exercise in cystic fibrosis. Pediatr Pulmonol 1990;8:162-7.

10 Prendiville A, Rose A, Maxwell DL, Silverman M. Hypoxaemia in wheezy infants after bronchodilator treatment. Arch Dis Child 1987;62:997-1000.
11 Hedlin G, Freyschuss V, Hedenstierna G. Histamineinduced asthma in children: effects on the ventilationperfusion relationship. Clin Physiol 1987;5:19-34.

12 Buhr Jorres R, Berdel D, Landser FJ. Correspondence between forced oscillation and body plethysmography during bronchoprovocation with carbachol in children. Pediatr Pulmonol 1990;8:280-8.

13 Solymar L, Arousson PH, Blake B, Bjure J. Respiratory resistance and impedance magnitude in healthy children aged 2-18 years. Pediatr Pulmonol 1985;1:134-40.

14 Duiverman EJ, Neijens HJ, van der Snee-van Smaalen $M$, Kerrebijn KF. Comparison of forced oscillometry and forced expirations for measuring dose-related responses to inhaled metacholine in asthmatic children. Bull Eur Physiol Respir 1986;27:433-6. 